\title{
Descentralização Organizacional, Acesso aos Meios e Adequação ao Ambiente Externo
}

\author{
Tarcízio Rego Quirino
}

\section{RESUMO}

As decorrências da descentralização e suas ligações com o atendimento da demanda, são estudadas em uma organização de pesquisa agropecuária, usando dados de 3 questionários referentes a 2011 projetos de pesquisa em andamento, preenchidos por pesquisadores, coordenadores de projetos e chefes adjuntos técnicos. Desempenho, insumos, processamento e ambiente externo estão empiricamente relacionados com descentralização, como prediz a teoria contingencial. Pesquisas executadas centralizadamente se beneficiam da qualidade dos recursos humanos e do acesso à informação. Pesquisas descentralizadas se beneficiam da proximidade com os usuários. Como consequiência, centralização sugere maior qualidade acadêmica; descentralização, maior impacto na prática agrícola. Uma agenda de descentralização é benéfica às demandas dos produtores, mas exige que se garanta acesso aos meios (recursos físicos, humanos, econômicos e organizacionais), pois estes tendem a ser insatisfatórios nas condições usuais de descentralização.

Palavras-chaves: centralização organizacional; organizações de C\&T; pesquisa agropecuária; desempenho organizacional; qualidade da pesquisa.

\begin{abstract}
Results of decentralization and its relationships to demand satisfaction are studied in an organization of agricultural research. Three questionnaires relative to 2011 research projects in progress, filled by researchers, project coordinators and technical directors generated the data. Performance, inputs, process and external organizational environment are found to be empirically related to decentralization as predicted by contingencial theory. Centralized research benefits from human resource quality and access to information. Decentralized research benefits from users' proximity. As a consequence, centralization suggests academic quality and decentralization suggests stronger impact in agricultural practice. A decentralization agenda should be beneficial to the producers' demands as far as access to the means (physical, human, economic and organizational resources) is provided as they use to be unsatisfactory in typical decentralized conditions.
\end{abstract}

Key words: organizational centralization; organizations of C\&T; agricultural research; organizational performance; research quality. 


\section{INTRODUÇÃO}

Terceirização e descentralização se acham entre as mais insistentes demandas feitas recentemente a firmas, corporações, Governos e empresas em geral, e a organizações de pesquisa em particular (Naisbitt e Aburdene, 1990; External Appraisal Mission, 1992; BCA, 1995). Concomitantemente, a qualidade total e a atenção às demandas dos clientes são elevadas à posição de importância nunca antes recebida. Como resultado, descentralização e atenção à demanda da clientela se tornaram temas importantes na lista de preocupações dos gerentes e na carteira de pesquisas dos estudiosos. É necessário saber, por um lado, como se descentraliza e como se atende a demandas dos consumidores e, por outro, que esperar em decorrência desses processos.

O presente estudo visa a contribuir para o segundo aspecto: quais as decorrências da descentralização e como esta se liga ao grau de atendimento da demanda dos clientes, ou seja, como se adequar a este aspecto do ambiente externo. O campo de interesse específico é a administração de pesquisa, com perspectiva metodológica de análise sincrônica; porém a lógica em que o estudo se baseia convida a maiores generalizações, pelo menos de forma experimental ou indicativa.

Para examinar as relações entre descentralização, acesso aos meios e adequação ao ambiente externo, serão usados dados referentes a projetos de pesquisa agropecuária em que se observam condições de centralização e de descentralização no que se refere à execução das pesquisas. Um amplo projeto de avaliação e de planejamento estratégico, levado a efeito pela Empresa Brasileira de Pesquisa Agropecuária (EMBRAPA), permitiu a coleta de dados relevantes, como se explica mais adiante.

Depois de delinear as bases teóricas que fundamentam a análise, o artigo descreverá o material empírico e as circunstâncias em que foi coletado. Em seguida, serão examinadas as relações entre aspectos organizacionais teoricamente relevantes: desempenho, insumos, processamento e ambiente externo. Finalizando, as conclusões se aplicam a discernir os aspectos positivos e os negativos da descentralização, e a sugerir mudanças para manter os positivos e evitar ou inibir os negativos. 


\section{Os Correlatos da Centralização: as Bases Teóricas}

A centralização tem características e resultados reconhecidos pela literatura organizacional. Definida como "o grau em que o poder está centralizado em um sistema social" (Price, 1972), de tal modo que "o grau máximo de centralização existiria, se todo o poder fosse exercido por um único indivíduo", centralização "está ligada aos fatores de tamanho, tecnologia, ambiente e escolhas feitas no interior das organizações" (Hall, 1977).

A teoria contingencial prediz, porém, que os resultados da centralizaçãodescentralização serão positivos ou negativos, dependendo do tipo de organização em que esta acontece. Hage e Finsterbusch (1987), ao contraporem quatro modelos organizacionais no contexto da teoria contingencial, enfatizam que o modelo orgânico-profissional é o mais apropriado para organizações de pesquisa, dentre as quais as de pesquisa agropecuária são citadas explícitamente. Em sua estrutura, o modelo orgânico-profissional se distingue dos demais ${ }^{(1)}$ no seguinte elenco:

. larga variedade de especialistas

. membros das profissões como administradores

. autoridade baseada na capacidade

. liderança mutável

. altamente igualitária

. papéis não definidos e responsabilidades mutáveis

. altamente descentralizada

A descentralização se faz uma condição tão importante nas organizações de pesquisa por causa do tipo de desempenho que, ainda segundo os mesmos autores, é delas requerido:

. produtos e serviços individualizados à demanda

. inovação

. alta qualidade

. adaptabilidade a condições mutantes 
O modelo, portanto, sustenta teoricamente a hipótese de que a centralização se correlaciona negativamente com o desempenho das organizações de pesquisa agropecuária. Além disso, prediz que a centralização está correlacionada com aspectos da estrutura, dos recursos, dos pontos fracos, das contingências ambientais, da cultura e dos processos organizacionais.

No caso da pesquisa agropecuária, é razoável esperar que a descentralização dos projetos de pesquisa venha a representar um instrumento, para que se consiga um desempenho mais inovativo, de melhor qualidade e, sobretudo, mais individualizado e mais adaptado a condições mutantes. Durante as diversas fases do ciclo de produção dos conhecimentos e tecnologias decorrentes da pesquisa agropecuária, o grau de centralização varia consideravelmente, como se pode depreender das relações entre projetos, programas e planos diretores. É provável e esperável, porém, que a realização descentralizada dos projetos seja uma oportunidade para que a organização afine a sintonia com os problemas e com as clientelas locais.

Com a finalidade de verificar até que ponto as expectativas teóricas são confirmadas pela instância empírica em consideração, a seguir serão examinadas as relações entre centralização, no contexto dos programas de pesquisa da EMBRAPA $^{(2)}$ e os aspectos relevantes de desempenho e do acesso aos meios, tais como insumo, processamento e ambiente externo referentes às pesquisas incluídas em cada programa. Conquanto o objetivo primordial do projeto tenha sido de ordem prático-administrativa, um exame dos dados com interesse teórico se torna oportuno. Evidências positivas favoráveis à teoria certamente fortalecerão a confiança que nela se pode depositar e, atentando ao dito de que nada mais prático do que uma boa teoria, encorajarão a aplicação mais conseqüiente da teoria contingencial na gestão de ciência e tecnologia.

\section{Os Dados}

Pela sistemática implementada desde a época de sua criação, e vigente até 1992 , cada Programa Nacional de Pesquisa (PNP), a unidade maior do sistema de planejamento, é composto fundamentalmente de projetos de pesquisa e se subordina a um Centro de Pesquisa Agropecuária, cujo chefe tem a responsabilidade de coordená-lo. Geralmente a coordenação é delegada por este a um pesquisador de notório saber e experiência, devido ao acúmulo de outras obrigações que, no centro e fora dele, disputam as atenções do chefe. A abrangência do PNP pode incluir pesquisas executadas no centro que o coordena, assim como outras, executadas em unidades de pesquisa da própria EMBRAPA, dos Estados, de universidades e de organizações nacionais, internacionais e estrangeiras. 
A temática dos PNPs tem seguido de perto as especializações das unidades de pesquisa. Há programas por produto (exemplo: feijão, maçã), que abrangem em princípio todo o país e são, usualmente, coordenados pelo Centro Nacional, em cujo mandato se inclui; há programas por recursos (exemplo: recursos naturais do trópico semi-árido) que, sob a coordenação do respectivo Centro de Recursos, se voltam para as regiões edafoclimáticas, onde estes são típicos; tem havido programas especiais, com a finalidade de fazer avançar o conhecimento sobre um tema de interesse prioritário, como o de energia alternativa, coordenados por um centro escolhido por apresentar vantagens comparativas para tal, ou até mesmo por uma unidade da sede.

Os recursos financeitos para os PNPs são alocados a cada um deles pela diretoria, à luz de pareceres técnicos do Departamento de Planejamento e Desenvolvimento da Pesquisa (DPD), anteriormente cognominado, por um longo período, de Departamento Técnico Científico (DTC). Neste sistema, a gerência dos recursos, tanto financeiros como físicos, humanos e organizacionais, é feita, em princípio, pelo chefe da unidade coordenadora, ficando o coordenador do PNP com a responsabilidade gerencial dos aspectos científicos.

Essa descrição sumária mostra, por um lado, como a figura do PNP é central para o sistema de pesquisa da EMBRAPA e de todo o Sistema Cooperativo de Pesquisa Agropecuária e, por outro, como o PNP está entrelaçado com tudo o que se faz em cada unidade de pesquisa e como abrange e contém os projetos em sua concepção, execução e aplicação dos resultados. Por este motivo, o satisfatório andamento dos programas e, concomitantemente, sua avaliação sistemática, tornam-se ferramentas de inexcedível utilidade para o correto gerenciamento de C\&T e para o incremento da qualidade da pesquisa e da responsividade da empresa.

Os dados usados a seguir se baseiam na avaliação dos 2011 projetos em andamento referentes a todos os programas de pesquisa da EMBRAPA, segundo descrito em Quirino, Cruz e Souza (1992) e Souza, Cruz e Quirino (1993a, 1993b). Foram coletados por ocasião da pesquisa Diagnóstico de Projetos (nov./90), em meio eletrônico, com uso de 3 questionários respondidos respectivamente pelo chefe técnico da unidade, pelo pesquisador responsável do projeto e pelo coordenador nacional do programa.

\section{Centralização}

As medidas de centralização usadas na literatura organizacional são, as mais das vezes, de dois tipos: coletam dados sobre poder, no que diz respeito a tipos 
definidos de decisão, ou então usam questões para identificar poder ou influência em geral. Quase não há medidas de centralização baseadas em dados objetivos (Price, 1972). No presente estudo, a centralização foi medida de modo objetivo (isto é, não intermediado pela percepção dos atores sociais) e representa o grau de poder relativo do centro com respeito a cada uma das pesquisas sendo ali realizadas. Isto implica diferenças de poder em geral, bem como de poder decisório sobre aspectos pré-estabelecidos da pesquisa. Assim, a superposição, no mesmo centro e sob a responsabilidade do mesmo chefe, da coordenação do PNP e da coordenação e implementação de pesquisas a este pertencentes, é uma instância empírica, que satisfaz o conceito teórico de centralização. Há centralização nos casos em que o poder de coordenar o PNP coincide com o poder de coordenar a pesquisa. Há descentralização nos casos em que o poder de coordenar a pesquisa é atribuído a um centro que não detém o poder de coordenar o respectivo PNP.

Até que ponto a centralização se relaciona com os aspectos organizacionais da pequisa? Como pode esta relação ser identificada nos dados empíricos?

A tendência à centralização observada na EMBRAPA, na vigência dos arranjos organizacionais acima descritos, pode ser identificada sob a perspectiva dos programas. Dentre os 57 programas em atividade, apenas $11(19,3 \%)$ desenvolvem externamente metade ou mais de seus projetos, sendo que $24(42,1 \%)$ retiveram três quartos dos projetos para serem desenvolvidos em casa, isto é, na própria unidade coordenadora do PNP.

A Tabela 1 resume a situação dos programas, agora sob a perspectiva dos projetos, e mostra que mais da metade das pesquisas é executada na mesma unidade que coordena o respectivo PNP. Em resumo, 58,2\% das pesquisas executadas são coordenadas pela própria unidade.

\section{Tabela 1: Centralização dos Programas: Comparação entre Coordenação e Local de Execução dos Projetos de Pesquisa}

\begin{tabular}{lcc}
\hline \multicolumn{1}{c}{ Centralização } & Execução & $\%$ \\
& $\mathrm{~N}^{\underline{0}}$ & $(2011)$ \\
\hline Na mesma unidade de coordenação (centralizada) & 1171 & 58,2 \\
Em outra unidade (descentralizada) & 544 & 27,1 \\
Sem informação & 296 & 14,7 \\
\hline
\end{tabular}

O grau de centralização se torna ainda mais evidente, se as porcentagens da Tabela 1 forem recalculadas com a exclusão dos projetos sobre os quais não há informação: 68,3\%, isto é, mais de dois terços, são executados em casa. 
O nível de retenção que uma unidade de pesquisa pratica sobre os projetos, executando ela própria mais da metada deles, é a medida dicotomizada de centralização que vai ser usada. Assim, será possível testar sua relação com os diferentes aspectos de desempenho das unidades de pesquisa e identificar o que se pode esperar da descentralização.

\section{Centralização e Desempenho}

Os dados sobre os programas de pesquisa, por se referirem a pesquisas em andamento, não incluem medidas do resultado final dos projetos nem evidências sobre a aplicação dos conhecimentos e das tecnologias, pois estes, no momento da coleta, estavam ainda sendo gerados (Quirino, Cruz e Souza, 1992). O problema do desempenho foi, pois, abordado no contexto do projeto em andamento, por meio da comparação entre o planejado e o executado, por um lado, e do realizável ou antecipado como possível de realizar, por outro. A presente análise examina se os projetos centralizados, isto é, aqueles que são executados nas unidades coordenadoras dos respectivos programas, apresentam diferenças de andamento em relação aos descentralizados.

Os dados indicam que não há diferença significativa entre projetos centralizados e descentralizados, no que concerne ao cumprimento do cronograma previsto. Em ambos os casos, apenas cerca de $65 \%$ do planejado havia de fato sido cumprido até o momento da coleta de dados. O mesmo acontece com a previsão que se fez para o futuro. Foi previsto que, no final do prazo planejado, projetos centralizados e descentralizados conseguiriam, indistintamente, cumprir cerca de $78 \%$ de seus cronogramas (vide Tabela 2).

\section{Tabela 2: Centralização e Desempenho de Projetos em Andamento}

\begin{tabular}{lccc}
\hline Cumprimento dos Cronogramas & & $\begin{array}{c}\text { Centralizado } \\
(\mathrm{N}=1052) \\
\text { Média }\end{array}$ & $\begin{array}{c}\text { Descentralizado } \\
(\mathrm{N}=487) \\
\text { Média }\end{array}$ \\
\hline Ações programadas até o presente & NS & $65,4 \%$ & $65,5 \%$ \\
Previsto de atingimento no prazo & NS & $78,9 \%$ & $78,6 \%$ \\
\hline
\end{tabular}

* - Medidas significativamente diferentes entre unidades sede do PNP e outras unidades $(\mathrm{P}<0,05)$

NS - Diferença não significante

Faz parte do princípio que inspira e sustenta o setor público a idéia de que a 
organização funciona para obter produtos e serviços de tipos tais que satisfaçam as demandas da sociedade. O funcionamento das organizações de pesquisa agropecuária resulta na produção de conhecimentos e tecnologias que, para serem individualizados para a demanda, requerem um modelo organizacional descentralizado. A Tabela 3 relaciona os tipos de produtos dos diferentes projetos de pesquisa e o grau de centralização das pesquisas que os geram, no que se refere à coordenação dos programas.

\section{Tabela 3: Centralização e Tipos de Produtos da Pesquisa}

\begin{tabular}{lccc}
\hline Produtos & & $\begin{array}{c}\text { Centralizado } \\
(\mathrm{N}=1023) \\
\%\end{array}$ & $\begin{array}{c}\text { Descentralizado } \\
(\mathrm{N}=398) \\
\%\end{array}$ \\
\hline Tecnologias de produção agropecuária & $\mathrm{NS}$ & 30,5 & 52,6 \\
Métodos e tecnologias de pesquisa & $*$ & 39,6 & 31,7 \\
Conhecimentos novos para o avanço da ciência & $\mathrm{NS}$ & 33,9 & 30,3 \\
Variedades vegetais ou raças animais & $*$ & 26,5 & - \\
Conhecimento sobre recursos naturais & $\mathrm{NS}$ & 24,0 & 41,9 \\
Tecnologias de proteção ambiental & $*$ & 22,1 & 15,1 \\
Insumos agropecuários & $\mathrm{NS}$ & 12,3 & 12,9 \\
Conhecimento sobre aspectos sócio-econômicos & $\mathrm{NS}$ & 13,3 & 12,5 \\
Processamento e preservação de produtos & $\mathrm{NS}$ & 6,7 & 8,8 \\
Máquinas, equipamentos, implementos ou & $\mathrm{NS}$ & 2,8 & 1,8 \\
instrumentação agropecuária & & & \\
\hline
\end{tabular}

* - Probabilidade de diferença $<0,05$ (Teste do $\mathrm{X}^{2}$ )

NS - Não significante

Dos 10 tipos de produtos gerados pela pesquisa agropecuária da EMBRAPA, 3 apresentam diferenças quanto à centralização. Métodos e tecnologias de pesquisa são gerados em proporções significativamente maiores nas unidades que desenvolvem as pesquisas dos seus próprios programas, do que naquelas cuja pesquisa é descentralizada. O mesmo se dá com tecnologias de proteção ambiental. Pelo contrário, os resultados referentes a variedades vegetais ou raças animais são oriundos, em maior proporção, de pesquisas descentralizadas.

Portanto, usando o mesmo ritmo de cumprimento dos cronogramas, as pesquisas centralizadas produzem mais instrumentos para gerar novas pesquisas e defender a natureza, enquanto as descentralizadas geram mais resultados de uso direto da produção agropecuária. 


\section{Centralização e Acesso aos Meios}

$\mathrm{O}$ acesso a meios suficientes, que permitam produzir os resultados demandados das pesquisas, revelou-se muito diferenciado de acordo com o grau de centralização. As pesquisas realizadas nas unidades coordenadoras do respectivo PNP têm acesso mais abundante e fácil a quase todos os tipos de meios. Apresentam-se como exceção, os prazos previstos para a execução dos projetos e os recursos aprovados, por não diferirem significativamente em decorrência do nível de centralização. Os projetos centralizados se beneficiam, porém, de muito mais interdisciplinaridade e tamanho da equipe, infra-estrutura suficiente para execução, envolvimento de outras instituições, tempo dedicado pela equipe e sua qualificação. Todas as diferenças são de mais de 10 pontos percentuais a favor das pesquisas centralizadas, chegando a 23 pontos no que se refere à interdisciplinaridade e tamanho da equipe. Esses resultados, mostrados na Tabela 4, podem indicar que as pesquisas centralizadas são de nível mais alto de complexidade do que as demais.

\section{Tabela 4: Centralização e Acesso aos Meios}

\begin{tabular}{lccc}
\hline Suficiência & & $\begin{array}{c}\text { Centralizado } \\
(\mathrm{N}=1050)\end{array}$ & $\begin{array}{c}\text { Descentralizado } \\
(\mathrm{N}=489) \\
\%\end{array}$ \\
\hline Prazo previsto para execução do projeto & $\mathrm{NS}$ & 69,7 & 66,9 \\
Recursos aprovados & $\mathrm{NS}$ & 54,7 & 53,2 \\
Infraestrutura para execução & $*$ & 73,8 & 51,9 \\
Interdisciplinaridade da equipe & $*$ & 73,3 & 49,7 \\
Tamanho da equipe & $*$ & 71,3 & 47,8 \\
Tempo dedicado pela equipe & $*$ & 77,6 & 60,3 \\
Qualificação da equipe & $*$ & 87,0 & 64,2 \\
Envolvimento de outras instituições & $*$ & 77,8 & 57,8 \\
\hline
\end{tabular}

* - Probabilidade de diferença $<0,05$ (Teste do $\left.\mathrm{X}^{2}\right)$

NS - Não significante

Além disso, três fatores afetam desigualmente as pesquisas, com relação ao grau de centralização. As condições climáticas, a atuação da unidade coordenadora do PNP e a existência de erro técnico de planejamento prejudicam sobretudo as pesquisas descentralizadas. Obviamente, diferenças de condições climáticas não são relacionadas com centralização, mas a resistência a condições climáticas negativas pode ser determinada por maior acesso aos meios nas unidades que praticam a centralização. Tanto os fatores referentes à disponibilidade de recursos financeiros, humanos e físicos, que afetam mais negativamente a execução dos projetos em geral, como aqueles referentes à disponibilidade de material básico e de apoio administrativo, de recursos bibliográficos e de informática incidem 
por igual sobre os programas, independentemente de estarem sendo executados na unidade coordenadora ou fora desta (vide Tabela 5).

\section{Tabela 5: Centralização e Fatores que Afetam Negativamente a Execução do Projeto}

\begin{tabular}{lccccc}
\hline Fatores & & \multicolumn{2}{c}{$\begin{array}{c}\text { Centralizado } \\
(\mathrm{n}=1050)\end{array}$} & \multicolumn{2}{c}{$\begin{array}{c}\text { Descentralizado } \\
(\mathrm{N}=489)\end{array}$} \\
\hline & & Média & $\begin{array}{c}\text { Desvio } \\
\text { padrão } \\
\text { (escala 0-7) }\end{array}$ & Média & $\begin{array}{c}\text { Desvio } \\
\text { padrão } \\
\text { (escala 0-7) }\end{array}$ \\
\hline Disponibilidade de recursos financeiros & NS & 2,369 & 2,475 & 2,429 & 2,433 \\
Disponibilidade de recursos humanos & NS & 2,237 & 2,277 & 2,270 & 2,315 \\
Disponibilidade de recursos físicos & NS & 1,702 & 2,173 & 1,501 & 2,063 \\
Disponibilidade de material básico & NS & 1,622 & 2,208 & 1,593 & 2,149 \\
Condições climáticas & $*$ & 1,202 & 1,909 & 1,558 & 2,202 \\
Apoio administrativo & NS & 0,914 & 1,603 & 0,808 & 1,388 \\
Disponibilidade de recursos bibliográficos & NS & 0,780 & 1,513 & 0,845 & 1,510 \\
informática & & & & & \\
Atuação da unidade coordenadora do PNP & $*$ & 0,329 & 0,985 & 0,763 & 1,541 \\
Outras & NS & 0,349 & 1,356 & 0,366 & 1,382 \\
Erro técnico de planejamento & $*$ & 0,210 & 0,768 & 0,327 & 1,032 \\
\hline
\end{tabular}

* - Médias significativamente diferentes entre unidades sede do PNP e outras unidades $(\mathrm{P}<0,05)$

NS - Diferença não significante

A qualidade da pesquisa pode ser melhorada, se o acesso a determinados tipos de meios for facilitado. A Tabela 6 tem seus ítens ordenados de acordo com a prioridade que a eles foi dada pelo inteiro conjunto de projetos estudados, e pode ser interpretada como lista de demandas de melhoria (Quirino, Cruz e Souza, 1992); contudo, diferentemente do estudo citado, as médias foram aqui calculadas e comparadas para identificar diferenças de prioridades decorrentes do grau de centralização dos projetos. Os resultados demonstram que, em 8 dos 18 ítens testados, a demanda é significativamente diferente entre os projetos centralizados e os descentralizados.

Em todos os casos em que isto ocorre, a demanda é mais forte com referência aos projetos descentralizados (vide Tabela 6). As unidades que coordenam e executam seus projetos levantam a lista de reivindicações na ordem idêntica ao total, pois dão o tom a este. Os dados referentes a pesquisas descentralizadas, pelo contrário, chamam a atenção para alguns ítens em ordem diferente. Logo depois do pessoal de apoio de campo, surge a necessidade de equipamentos e instrumental permanente de campo, mostrando que no campo está um dos problemas centrais das executoras de projetos descentralizados. Consultoria e assessoria de especialistas, que para os projetos centralizados aparece apenas em sétimo lugar, para os outros sobe ao terceiro posto, logo seguido de recursos bibliográficos e acesso à informação. Material 
de consumo e peças de reposição de campo e veículos sobem, respectivamente, de oitavo para quinto e de undécimo para sexto lugar. Em compensação, equipamentos e instrumentos permanentes de laboratório e de informática se apresentam como menos urgentes, no caso das pesquisas descentralizadas.

\section{Tabela 6: Centralização e Recursos para Melhorar a Qualidade da Pesquisa (0-7)}

\begin{tabular}{lccc}
\hline Fatores & & $\begin{array}{c}\text { Centralizado } \\
(\mathrm{N}=1052) \\
\text { Média }\end{array}$ & $\begin{array}{c}\text { Descentralizado } \\
\text { (N = 487) } \\
\text { Média }\end{array}$ \\
\hline Pessoal de apoio de campo & $*$ & 3,446 & 4,080 \\
Equipamento e instrumental permanente de laboratório & $\mathrm{NS}$ & 3,252 & 2,996 \\
Recursos bibliográficos e acesso a informação & $*$ & 3,046 & 3,329 \\
Equipamento e instrumental permanente de informática & $\mathrm{NS}$ & 3,047 & 2,975 \\
Material de cons. e peças de reposição para laboratório & $\mathrm{NS}$ & 2,685 & 3,400 \\
Equipamento e instrumental permanente de campo & $*$ & 2,027 & 2,770 \\
Consultoria e assessoria de especialistas & $*$ & 2,644 & 3,353 \\
Material de consumo e peças de reposição de campo & $*$ & 2,615 & 3,294 \\
Pessoal de apoio de manutenção & $*$ & 2,758 & 2,702 \\
Pesquisadores & $*$ & 2,636 & 2,957 \\
Veículos & $*$ & 2,320 & 3,057 \\
Material de cons. e peças de reposição para informática & $\mathrm{NS}$ & 1,632 & 1,704 \\
Pessoal de apoio de manutenção & $*$ & 2,168 & 2,497 \\
Pessoal de apoio administrativo & $\mathrm{NS}$ & 1,632 & 1,704 \\
Equipamento e instrumental perm. casa de vegetação & $\mathrm{NS}$ & 1,516 & 1,657 \\
Equipamento e instrumental permanente para escritório & $\mathrm{NS}$ & 1,518 & 1,643 \\
Material de cons. e peças de reposição para escritório & $\mathrm{NS}$ & 1,472 & 1,583 \\
Material de cons. e peças de reposição casa e vegetação NS & 1,418 & 1,556 \\
\hline
\end{tabular}

* - Médias significativamente diferentes entre unidades sede do PNP e outras unidades $(\mathrm{P}<0,05)$

NS - Diferença não significante

Em resumo, a centralização dos programas afeta o acesso aos meios de que as diferentes unidades da organização de pesquisa agropecuária necessitam para produzir conhecimentos e tecnologias. Em geral, as pesquisas realizadas nas unidades, que coordenam o PNP de que fazem parte, têm melhor acesso aos meios, principalmente àqueles mais relacionados com a mobilização das capacidades dos recursos humanos e das organizações. Além disso, fatores negativos, tais como condições climáticas, atuação da coordenação e erro técnico de planejamento são mais encontrados nas pesquisas descentralizadas.

Os resultados sugerem ainda que as pesquisas centralizadas se desenvolvem em ambiente mais rico de meios, enquanto as demandas para as pesquisas descentralizadas reivindicam o básico, como material de campo, consultoria, bibliografia e acesso à informação. 


\section{Centralização e Processamento}

A adequação das hipóteses aos objetivos visados pela pesquisa, tanto da metodologia para testar as hipóteses, como da estrutura do projeto para resolver o problema de pesquisa, não difere entre os projetos que se desenvolvem na unidade coordenadora do PNP e os que são implementados alhures. As diferenças, favoráveis às unidades centralizadoras, se mostram na adequação dos recursos humanos e materiais; mas os problemas das pesquisas descentralizadas foram considerados de relevância mais duradoura, visto que esta, de acordo com o julgamento dos próprios coordenadores de PNP, mais freqüentemente se mantém atual com o correr do tempo (vide Tabela 7).

\section{Tabela 7: Centralização e Adequação dos Procedimentos de Pesquisa aos Objetivos dos Projetos}

\begin{tabular}{|c|c|c|c|c|c|c|c|}
\hline \multirow[b]{2}{*}{ Adequação } & & \multicolumn{4}{|c|}{ Centralizado } & \multicolumn{2}{|c|}{ Descentralizado } \\
\hline & & $\mathrm{N}$ & $\begin{array}{c}\text { Média } \\
\text { escala } \\
(0-7)\end{array}$ & $\begin{array}{l}\text { Desvio } \\
\text { padrão }\end{array}$ & $\mathrm{N}$ & $\begin{array}{c}\text { Média } \\
\text { (escala } \\
0-7 \text { ) }\end{array}$ & $\begin{array}{c}\text { Desvi } \\
\text { o } \\
\text { padrão }\end{array}$ \\
\hline $\begin{array}{l}\text { Das hipóteses aos objetivos da } \\
\text { pesquisa }\end{array}$ & NS & 901 & 6,094 & 1,045 & 384 & 5,997 & 1.127 \\
\hline $\begin{array}{l}\text { Da metodologia para testar as } \\
\text { hipóteses }\end{array}$ & NS & 898 & 6,066 & 1,042 & 387 & 6,067 & 1,048 \\
\hline Dos recursos humanos & $*$ & 1049 & 5,781 & 1,261 & 483 & 5,236 & 1,396 \\
\hline Dos recursos materiais & $*$ & 1050 & 5,334 & 1,407 & 483 & 5,085 & 1,262 \\
\hline Da relevância atual do problema & * & 912 & 6,182 & 1,140 & 397 & 6,373 & 0,925 \\
\hline $\begin{array}{l}\text { Da estrutura do projeto para resolver o } \\
\text { problema de pesquisa }\end{array}$ & NS & 910 & 5,709 & 1,307 & 396 & 5,768 & 1,297 \\
\hline
\end{tabular}

* - Medidas significativamente diferentes entre unidades sede do PNP e outras unidades $\mathrm{P}<0,05)$

NS - Diferença não significante

O enriquecimento dos projetos de pesquisa, tanto na concepção quanto na execução, se dá em níveis equivalentes, independentemente da centralização, seja ele decorrência das reuniões de programação ou das prioridades do PNP (vide Tabela 8), mas diferem as alterações que se fazem nos projetos para enriquecê-los. Primeiramente, os projetos centralizados fazem, percentualmente, o duplo de alterações não formalizadas ( $10 \%$ e 5\% respectivamente, vide Tabela 9). Depois, alterações que são feitas por via formal são mais freqüentes nos projetos descentralizados (62\%) do que nos centralizados (57\%), embora a diferença não atinja o nível de significância estatística requerido. 


\section{Tabela 8: Centralização e Enriquecimento dos Projetos de Pesquisa}

\begin{tabular}{lccccc}
\hline \multirow{2}{*}{ Melhoria do projeto } & \multicolumn{2}{c}{$\begin{array}{c}\text { Centralizado } \\
(\mathrm{n}=1050)\end{array}$} & \multicolumn{2}{c}{$\begin{array}{c}\text { Descentralizado } \\
(\mathrm{N}=489)\end{array}$} \\
\cline { 2 - 6 } & Média & $\begin{array}{c}\text { Desvio } \\
\text { padrão } \\
\text { (escala 0-7) }\end{array}$ & Média & $\begin{array}{c}\text { Desvio } \\
\text { padrão } \\
\text { (escala 0-7) }\end{array}$ \\
\hline Reunião de programação na concepção & & 3,774 & 2,137 & 3,583 & 2,293 \\
Prioridades do PNP na concepção & NS & 3,278 & 2,252 & 3,229 & 2,382 \\
Reunião de programação na execução & NS & 3,896 & 2,149 & 4,045 & 2,222 \\
Prioridades do PNP na execução & & & & &
\end{tabular}

NS - Diferença não significante

Tabela 9: Centralização e Alterações na Execução do Projeto em Relação à Proposta Inicial

\begin{tabular}{lccc}
\hline Alterações & & $\begin{array}{c}\text { Centralizado } \\
\mathrm{N}=1050) \\
\%\end{array}$ & $\begin{array}{c}\text { Descentralizado } \\
(\mathrm{N}=489) \\
\%\end{array}$ \\
\hline Não houve & $\mathrm{NS}$ & 33 & 33 \\
Houve, formalizadas por escrito & $\mathrm{NS}$ & 57 & 62 \\
Houve, não formalizadas & $*$ & 10 & 5 \\
\hline
\end{tabular}

\section{Tabela 10: Centralização, Modificações dos Projetos e Melhoria do Desempenho}

\begin{tabular}{|c|c|c|c|c|c|}
\hline \multirow[t]{2}{*}{ Melhoria do projeto } & & \multicolumn{2}{|c|}{$\begin{array}{c}\text { Centralizados } \\
(\mathrm{N}=1050)\end{array}$} & \multicolumn{2}{|c|}{$\begin{array}{c}\text { Descentralizado } \\
(\mathrm{N}=489)\end{array}$} \\
\hline & & Média & $\begin{array}{c}\text { Desvio } \\
\text { padrão } \\
\text { (escala 0-7) }\end{array}$ & Média & $\begin{array}{c}\text { Desvio } \\
\text { padrão } \\
\text { (escala 0-7) }\end{array}$ \\
\hline Objetivo: modificaram & NS & 0,400 & 1,230 & 0,362 & 1,063 \\
\hline Objetivo: melhoraram & $*$ & 1,229 & 1,948 & 1,000 & 1,758 \\
\hline Hipótese: modificaram & NS & 0,556 & 1,574 & 0,475 & 1,427 \\
\hline Hipótese: melhoraram & NS & 1,384 & 2,275 & 1,207 & 2,146 \\
\hline Metodologia: modificaram & NS & 0,317 & 1,078 & 0,237 & 0,847 \\
\hline Metodologia: melhoraram & NS & 1,525 & 2,219 & 1,616 & 2,256 \\
\hline Estratégia: modificaram & NS & 0,392 & 1,288 & 0,307 & 1,145 \\
\hline Estratégia: melhoraram & NS & 1,305 & 2,224 & 1,221 & 2,098 \\
\hline Equipe: modificaram & NS & 1,618 & 1,980 & 1,624 & 2,023 \\
\hline Equipe: melhoraram & NS & 1,685 & 2,380 & 1,544 & 2,299 \\
\hline Prazo de execução: modificaram & NS & 1,945 & 2,457 & 1,961 & 2,464 \\
\hline Prazo de execução: melhoraram & NS & 1,392 & 2,356 & 1,219 & 2,188 \\
\hline
\end{tabular}

* - Médias significativamente diferentes entre unidades sede do PNP e outras unidades $(\mathrm{P}<0,05)$

NS - Diferença não significante 
Os projetos centralizados mais freqüentemente melhoraram os objetivos das pesquisas do que os descentralizados, embora não se observem diferenças significantes no grau em que as unidades modificaram seus projetos. No que se refere aos demais aspectos, em que os projetos foram modificados ou melhorados, não se apresentam diferenças oriundas da centralização (vide Tabela 10).

É mais comum que os projetos descentralizados sejam alterados por recomendações da unidade coordenadora do PNP. É mais comum que os projetos centralizados sejam alterados por aparecimento de novas informações na literatura ou na própria execução do projeto. As demais razões para alteração não mostraram relação significante com a centralização (vide Tabela 11).

Tabela 11: Centralização e Razões para Alteração dos Projetos

\begin{tabular}{lccccc}
\hline \multirow{2}{*}{ Razão } & & \multicolumn{2}{c}{$\begin{array}{c}\text { Centralizado } \\
(\mathrm{n}=1050)\end{array}$} & \multicolumn{2}{c}{$\begin{array}{c}\text { Descentralizado } \\
(\mathrm{N}=489)\end{array}$} \\
\cline { 3 - 7 } & & Média & $\begin{array}{c}\text { Desvio } \\
\text { padrão } \\
\text { (escala 0-7) }\end{array}$ & Média & $\begin{array}{c}\text { Desvio } \\
\text { padrão } \\
\text { (escala 0-7) }\end{array}$ \\
\hline Recomendação Unidade coordenadora do PNP & $*$ & 0,671 & 1,567 & 0,922 & 1,822 \\
Recomendações reunião programação do PNP NS & 0,992 & 1,828 & 1,027 & 1,919 \\
Saída de pesquisador para pós-graduação & NS & 0,772 & 1,819 & 0,869 & 1,958 \\
Saída de pesq. Outras Unidades ou instituições & NS & 0,751 & 1,880 & 0,683 & 1,726 \\
Aparecimento de novas inform. na literatura & $*$ & 1,145 & 2,018 & 0,751 & 1,603 \\
Disponibilidade de recursos materiais & NS & 1,498 & 2,320 & 1,524 & 2,253 \\
Disponibilidade de recursos humanos de apoio & NS & 1,508 & 2,241 & 1,462 & 2,192 \\
Disponibilidade de recursos financeiros & NS & 1,570 & 2,391 & 1,528 & 2,312 \\
Erro técnico de planejamento & NS & 0,308 & 1,038 & 0,403 & 1,267 \\
Aparecimento novas inform. na exec. do & $*$ & 2,008 & 2,594 & 1,391 & 2,208 \\
projeto & & & & & \\
Outras causas & NS & 0,724 & 1,933 & 0,810 & 2,004 \\
\hline
\end{tabular}

* - Médias significativamente diferentes entre unidades sede do PNP e outras unidades $(\mathrm{P}<0,05)$

NS - Diferença não significante

Centralizadas ou descentralizadas, as pesquisas envolvem outras unidades da EMBRAPA e outras organizações na sua execução. Será que o nível de centralização se relaciona com a capacidade ou com a necessidade de envolver maior número de organizações na execução das pesquisas? A Tabela 12 demonstra que as diferenças se revelam em quatro tipos de organização, pois metade das diferenças de médias são estatisticamente significantes. As pesquisas centralizadas apresentam médias de envolvimento superiores em se tratando de instituições estaduais de pesquisa agropecuária, empresas privadas e agências de financiamento. As descentralizadas atraem mais parceiros para o envolvimento apenas quando se trata de outras unidades da EMBRAPA. 


\section{Tabela 12: Centralização e Instituições Envolvidas na Execução de Projetos (Média por Pesquisa)}

\begin{tabular}{|c|c|c|c|c|c|}
\hline \multirow[t]{2}{*}{ Fatores } & & \multicolumn{2}{|c|}{$\begin{array}{c}\text { Centralizado } \\
(\mathrm{n}=1050)\end{array}$} & \multicolumn{2}{|c|}{$\begin{array}{c}\text { Descentralizado } \\
(\mathrm{N}=489)\end{array}$} \\
\hline & & Média & $\begin{array}{c}\text { Desvio } \\
\text { padrão } \\
\text { (escala 0-7) }\end{array}$ & Média & $\begin{array}{c}\text { Desvio } \\
\text { padrão } \\
\text { (escala 0-7) }\end{array}$ \\
\hline Outras unidades da EMBRAPA & * & 0,474 & 1,730 & 1,231 & 5,151 \\
\hline Instituições estaduais de pesquisa agropec. & $*$ & 0,566 & 1,598 & 0,209 & 0,685 \\
\hline Instituições internacionais & NS & 0,239 & 0,644 & 0,474 & 4,583 \\
\hline Empresas privadas & $*$ & 0,520 & 2,888 & 0,249 & 0,912 \\
\hline Universidades & NS & 0,420 & 2,110 & 0,446 & 4,036 \\
\hline Cooperativas & NS & 0,322 & 3,257 & 0,182 & 0,638 \\
\hline Instituições estaduais de extensão rural & NS & 0,212 & 0,855 & 0,342 & 2,841 \\
\hline Agências de financiamento & $*$ & 0,269 & 2,930 & 0,043 & 0,231 \\
\hline
\end{tabular}

* - Médias significativamente diferentes entre unidades sede do PNP e outras unidades $(\mathrm{P}<0,05)$

NS - Diferença não significante

Capilaridade institucional dos programas é, no contexto desta pesquisa, a soma de instituições que participam diretamente neles. Engloba as unidades executoras dos projetos descentralizados e as demais instituições envolvidas na pesquisa ou como cliente. Quando se quantificam os elos de ligação, isto é, as relações projeto/instituição que cada PNP foi capaz de gerar para fora da unidade coordenadora, o que mede a sua capilaridade, fica evidente que não existe diferença significativa entre a capilaridade das pesquisas centralizadas e aquela das pesquisas descentralizadas $(\mathrm{P}=0,56)$.

Em geral, seria de esperar que os grandes programas redundassem em mais alta capilaridade; porém não há padrão nítido nesta direção. Por exemplo, apenas um dos 5 maiores programas (recursos genéticos, aproveitamento do cerrado, avaliação do cerrado, hortaliças e pesquisa florestal) aparece entre os 5 programas de maior capilaridade (levantamento de solos, gado de leite, pesquisa florestal, milho e feijão). Cada programa de pesquisa apresenta capilaridade média entre 16,20 e 1,45 . Por outro lado, as grandes diferenças entre a média e a capilaridade máxima de determinada pesquisa, dentro de um programa (máxima das máximas: 684, no programa de solos), mostra que não há grande consistência entre as pesquisas de cada programa, devendo o nível de capilaridade ser atribuído sobretudo a características internas dos projetos, e não prioritariamente à variação entre os programas.

Por ser o aumento da capilaridade dos programas um dos caminhos para angariar parceiros e tornar a pesquisa mais presente na sociedade, este tema talvez 
mereça futuros estudos mais detalhados, depois de haver-se procedido ao devido aprofundamento teórico.

A imagem que se desenha sobre as relações entre centralização e processamento é a de que este é favorecido nas pesquisas centralizadas, por causa da adequação dos recursos humanos e materiais, do envolvimento mais freqüente de instituições externas à EMBRAPA e por causa do intenso aproveitamento das relações primárias entre pesquisadores mais capazes. Essa característica fica evidente pelo fato de que as alterações dos projetos se processam de modo informal nas pesquisas descentralizadas, que se aproveitam mais amiúde das novidades da literatura e dos resultados da própria pesquisa, enquanto nas pesquisas descentralizadas as alterações advêm, formalizadas, de sugestões dos coordenadores do PNP. Como resultado, observam-se mais melhorias nos objetivos das pesquisas centralizadas. Apesar de tudo isso, as pesquisas descentralizadas demonstram relevância mais duradoura dos problemas, no que se refere à necessidade de investigá-los. A centralização não ajuda nem prejudica a capilaridade.

\section{Centralização e Ambiente Externo}

Diversos aspectos de adequação do projeto de pesquisa foram examinados com o objetivo de identificar diferenças decorrentes da centralização. Há diferenças estatísticas significantes para indicar que os projetos descentralizados são mais adequados à missão e prioridades da unidade, enquanto os centralizados são mais convenientes à missão e aos objetivos do PNP. Da mesma forma, existe vantagem dos projetos centralizados no que se refere à adequação da estratégia de ação programada para atingir os objetivos do projeto, à consideração do provável efeito dos achados científicos sobre o meio ambiente e a qualidade de vida e à consideração do impacto sócio-econômico de seus achados científicos e tecnológicos. Os projetos descentralizados são mais adequados para alcançar, com sua execução, os objetivos propostos, para beneficiar o desenvolvimento da agropecuária e contribuir para o avanço do conhecimento científico mediante a solução do problema. Dois outros aspectos examinados não revelaram nenhuma diferença (vide Tabela 13).

As pesquisas desenvolvidas centralizadamente contam com recursos externos com mais freqüência do que as descentralizadas; contudo estas assinalaram maior potencial de comercialização, de captar recursos de órgãos públicos e organismos internacionais, embora a ligeira diferença não atinja os níveis estatisticamente requeridos. $\mathrm{O}$ mesmo se deu com relação à iniciativa privada que, diferentemente dos itens anteriores, favorece a parte centralizada dos PNPs (vide Tabela 14). 


\section{Tabela 13: Centralização e Adequação à Missão Organizacional}

\begin{tabular}{|c|c|c|c|c|c|c|c|}
\hline \multirow[b]{2}{*}{ Adequação } & & \multicolumn{4}{|c|}{ Centralizado } & \multicolumn{2}{|c|}{ Descentralizado } \\
\hline & & $\mathrm{N}$ & $\begin{array}{l}\text { Média } \\
\text { (escala } \\
0-7)\end{array}$ & $\begin{array}{l}\text { Desvio } \\
\text { padrão }\end{array}$ & $\mathrm{N}$ & $\begin{array}{c}\text { Média } \\
\text { (escala } \\
0-7)\end{array}$ & $\begin{array}{l}\text { Desvi } \\
\text { o } \\
\text { padrão }\end{array}$ \\
\hline Do proj. à missão e priorid. unidade & * & 1050 & 6,478 & 0,971 & 488 & 6,613 & 0,739 \\
\hline Do projeto à missão e objetivos PNP & * & 1023 & 6,267 & 1,001 & 398 & 5,707 & 1,527 \\
\hline Da estratégia p. atingir objet.do proj. & * & 888 & 5,916 & 1,148 & 345 & 5,725 & 1,228 \\
\hline $\begin{array}{l}\text { Do projeto considerando efeitos sobre } \\
\text { meio-ambiente e qualidade de vida }\end{array}$ & * & 1023 & 4,707 & 2,096 & 396 & 3,907 & 2,128 \\
\hline $\begin{array}{l}\text { Da identificação e definição do } \\
\text { problema }\end{array}$ & NS & 1050 & 6,183 & 0,973 & 488 & 6,207 & 1,025 \\
\hline $\begin{array}{l}\text { Para alcançar objetivos com execução } \\
\text { do projeto }\end{array}$ & * & 1050 & 6,057 & 1,011 & 488 & 6,209 & 1,004 \\
\hline $\begin{array}{l}\text { Na vinculação dos objetivos do proj. } \\
\text { ao problema }\end{array}$ & NS & 923 & 6,408 & 0,826 & 400 & 6,420 & 0,803 \\
\hline $\begin{array}{l}\text { Da solução do problema para } \\
\text { beneficiar o desenvolvimento da } \\
\text { agropecuária }\end{array}$ & * & 1046 & 6,010 & 1,132 & 488 & 6,246 & 0,958 \\
\hline $\begin{array}{l}\text { Da solução do problema para o } \\
\text { avanço do conhecimento científico }\end{array}$ & NS & 1048 & 5,134 & 1,729 & 488 & 5,318 & 1,699 \\
\hline
\end{tabular}

* - Médias significantemente diferentes entre unidades sede do PNP e outras unidades $(\mathrm{P}<0,05)$

NS - Diferença não significante

Tabela 14: Centralização e Potencial de Captação de Recursos

\begin{tabular}{lccc}
\hline Recursos & & $\begin{array}{c}\text { Centralizado } \\
(\mathrm{N}=1050) \%\end{array}$ & $\begin{array}{c}\text { Descentralizado } \\
(\mathrm{N}=489) \%\end{array}$ \\
\hline Iniciativa privada & $\mathrm{NS}$ & 45,7 & 43,2 \\
Órgãos públicos & $\mathrm{NS}$ & 51,2 & 55,6 \\
Organismos internacionais & $\mathrm{NS}$ & 36,0 & 38,2 \\
Potencial de comercialização & $\mathrm{NS}$ & 46,6 & 51,9 \\
Existência de recursos externos & $*$ & 15,6 & 7,6 \\
\hline
\end{tabular}

* - Probabilidade de diferença $<0,05$ (Teste do $\mathrm{X}^{2}$ )

NS - Não significante

Os quatro maiores usuários dos resultados (outros pesquisadores, agricultores e criadores, órgãos do Governo e empresas de comercialização de produtos agropecuários) não se diferenciam entre as pesquisas centralizadas ou não. A diferença aparece nos usuários menores: as indústrias de transformação se inclinam para usar os resultados das pesquisas descentralizadas, enquanto a indústria de insumos e a de máquinas e equipamentos se ligam às centralizadas (vide Tabela 15). 


\section{Tabela 15: Centralização e Usuários Imediatos dos Resultados}

\begin{tabular}{lccc}
\hline Usuários & & $\begin{array}{c}\text { Centralizado } \\
(\mathrm{N}=1023) \%\end{array}$ & $\begin{array}{c}\text { Descentralizado } \\
(\mathrm{N}=398) \%\end{array}$ \\
\hline Outros pesquisadores & $\mathrm{NS}$ & 88,0 & 85,1 \\
Agricultores e criadores & $\mathrm{NS}$ & 84,7 & 84,3 \\
Órgãos do governo & $\mathrm{NS}$ & 52,2 & 55,4 \\
Empresa de comercialização produtos agropecuários NS & 24,7 & 27,4 \\
Indústria de insumos & $*$ & 20,8 & 15,3 \\
Indústria de transformação & $*$ & 15,4 & 21,1 \\
Indústria de máquinas e equipamentos & $*$ & 9,4 & 4,5 \\
\hline
\end{tabular}

* - Probabilidade de diferença $<0,05$ (Teste do $\mathrm{X}^{2}$ )

NS - Não significante

Os projetos desenvolvidos centralizadamente usam três mecanismos de difusão dos resultados em proporções significativamente mais altas de que os demais: artigos científicos, apresentação em congressos e assembléias, e treinamentos e seminários. Embora todos os outros mecanismos de difusão sejam usados com mais freqüência para difundir os resultados dos projetos descentralizados, as diferenças são estatisticamente significantes apenas com referência a relatórios internos, visitas ativas e passivas de produtores e extensionistas, e dias de campo (vide Tabela 16). As diferenças de centralização podem ser sintetizadas por um quadro em que os projetos descentralizados aparecem como mais voltados para os objetivos finais das unidades e para o impacto da pesquisa na produção agropecuária, enquanto os centralizados se preocupam mais com os meios, os passos intermediários e os efeitos colaterais. Os projetos centralizados se preocupam mais com o que se passa antes da porteira da fazenda, e os descentralizados, depois. Os centralizados se comunicam mais com os pares e com os geradores de ciência e tecnologia; os descentralizados, com os produtores agropecuários.

\section{Tabela 16: Centralização e Mecanismos de Difusão dos Resultados}

\begin{tabular}{lccc}
\hline Mecanismos de difusão & & $\begin{array}{c}\text { Centralizado } \\
(\mathrm{N}=1050) \%\end{array}$ & $\begin{array}{c}\text { Descentralizado } \\
(\mathrm{N}=489) \%\end{array}$ \\
\hline Artigos científicos & $*$ & 84,4 & 79.4 \\
Relatórios internos & $*$ & 78,2 & 83,0 \\
Apresentação em congressos e assembléias & $*$ & 81,8 & 74,2 \\
Comunicados técnicos & $\mathrm{NS}$ & 76,2 & 79,6 \\
Treinamentos e seminários & $*$ & 75,1 & 64,2 \\
Visitas a/de produtos e extensionistas & $*$ & 65,2 & 77,5 \\
Publicações em rev. e jornais dirigidos ao produtor & $\mathrm{NS}$ & 64,9 & 67,5 \\
Dias de campo & $*$ & 56,6 & 63,2 \\
Palestras em coop. e associações de produtores & $\mathrm{NS}$ & 57,7 & 58,1 \\
Participação em progr. e entrevistas de rádio e TV & $\mathrm{NS}$ & 35,3 & 36,4 \\
Produção de áudios, filmes e vídeos & $\mathrm{NS}$ & 19,8 & 21,5 \\
\hline
\end{tabular}

* - Probabilidade de diferença $<0,05$ (Teste do $\mathrm{X}^{2}$ )

NS - Não significante 


\section{CONCLUSÕES}

O conjunto de dados provenientes da avaliação de projetos, aqui reanalizados sob novo ângulo, parece delinear um padrão, na qual pesquisas centralizadas nas unidades coordenadoras de PNP se beneficiam da qualidade dos recursos humanos e do acesso à informação, enquanto as pesquisas descentralizadas se beneficiam da proximidade com os usuários.

Como resultado, as primeiras sugerem mais alto nível de qualidade acadêmica, porém as descentralizadas sugerem maior impacto na prática agrícola. Tal padrão parece coerente com uma organização mobilizada e organizada em torno do conceito de centros de excelência, mas parece não atender plenamente aos requisitos de uma organização voltada para a produção de tecnologias que, sob a inspiração do conceito de P\&DD (Pesquisa e Desenvolvimento para o Desenvolvimento), se devote a maximizar o impacto na produção e na produtividade da agropecuária e a satisfazer diretamente as demandas e contingências da sociedade.

A natureza da centralização interna parece basear-se em uma espécie de reserva de mercado. As unidades coordenadoras de PNP procuram desenvolver o maior número possível de projetos viáveis, de modo que ocupem plenamente sua capacidade de produção, sublocando às demais unidades apenas o que seja por estas insistentemente reivindicado, ou o que exceda a capacidade de produção daquelas ou não satisfaçam seus sofisticados interesses científicos.

O quadro geral que os dados sugerem não é o ideal. Por um lado, as pesquisas centralizadas atendem os aspectos mais complexos e mais básicos das necessidades da agropecuária em geral, o que está de acordo com a divisão do trabalho entre as unidades de pesquisa adotada na concepção do modelo circular, antes praticado pela EMBRAPA, e pela pesquisa agropecuária de diversos países. Por outro, as pesquisas descentralizadas servem direta e preferencialmente os produtores agropecuários, mas são produzidas em condições claramente insatisfatórias de acesso aos recursos físicos, humanos, econômicos e organizacionais que deveriam garantir sua excelência. Finalmente, se a preocupação com os métodos e meios pode ser atendida a contento pelas pesquisas centralizadas, a preocupação com os efeitos colaterais, principalmente sobre o ambiente, deveria estar igualmente presente em todas as pesquisas.

Deste quadro emana uma agenda de descentralização que fortifica a capacidade de responder a contento às demandas mutantes dos usuários locais e corrige o viés eventualmente existente a favor dos núcleos de decisão representados pelo poder da coordenação central. Por outro lado, a expansão da missão da pesquisa 
agropecuária, que agora enfatiza claramente os segmentos do negócio agrícola localizados antes e depois da porteira do produtor, deve, neste contexto, ser gerida com competência e decisão, de modo a gerar resultados de impacto. Provavelmente este objetivo deve ser liderado pelas unidades mais bem aparelhadas para enfrentar a complexidade, gerar métodos e gerir processos, que são exatamente aquelas mais autônomas. Às demais unidades cabe dosar as duas vocações, de acordo com as demandas de seu ambiente mais próximo.

No caso da EMBRAPA, descentralizar apenas não é solução. É necessário viabilizar a qualidade das pesquisas descentralizadas para que seja possível aproveitar as vantagens que estas apresentam. Fortalecer as unidades periféricas, garantindo-lhes suficiente acesso aos meios, neste contexto, constitui problema prioritário da pesquisa agropecuária brasileira nos anos que vêm; deve incidir igualmente tanto sobre os meios materiais, como sobre os recursos humanos e os arranjos organizacionais.

\section{NOTAS}

${ }^{1}$ Modelo mecânico-burocrático (altamente centralizado), tradicional-artesanal (centralizado, mas com autonomia ocupacional) e misto mecânico-orgânico (centralizado em alguns aspectos e descentralizado em outros).

${ }^{2}$ As mudanças introduzidas na EMBRAPA a partir de 1992 (Silva e Flores, 1993) e a conseqüente adoção de um novo paradigma de administração estratégica (empresa com respondabilidade social) ensejaram, por um lado, a oportunidade para a avaliação dos programas e projetos de pesquisa que deram origem aos dados analisados na presente pesquisa e, por outro, a superação e reformulação do sistema de planejamento, acompanhamento e avaliação das pesquisas. O sistema atualmente vigente (Sistema EMBRAPA de Planejamento - SEP), regido pela Resolução Normativa 5/95 (BCA 08, 1995), e que incorpora as sugestões da Missão Internacional de Avaliação da EMBRAPA (External Appraisal Mission, 1992), se propõe ser mais descentralizado, mais aproximado da clientela e mais responsável perante a inspeção da sociedade. Para tal, funciona sob constante monitoramento de conselhos internos e externos de diferentes níveis, e adotou um modelo organizacional mais descentralizado, com maior separação entre os programas e as unidades. Além disso, o planejamento se baseia no levantamento das prioridades da agropecuária. Foi adotado também o rodízio entre centros da coordenação dos programas, assim como a eleição do coordenador por tempo limitado e independente dos mandatos dos chefes de centro. Em decorrência das mudanças introduzidas, seria mais difícil conseguir hoje dados empíricos que se prestassem para o estudo substantivo da descentralização, usando para tal um desenho metodológico baseado em mensurações sincrônicas, como o que aqui se apresenta; todavia a análise comparativa entre o antigo e o novo sistema certamente será de grande valor teórico e prático, mas não é o objetivo do presente estudo. 


\section{ReFERENCIAS BibliográfICAS}

BCA - BOLETIM DE COMUNICAÇÕES ADMINISTRATIVAS.

Resolução normativa $\mathrm{n}^{\circ} 8$ de maio de 1995. EMBRAPA, Brasília, 1995.

\section{EXTERNAL APPRAISAL MISSION.}

EMBRAPA global appraisal workshop report of the external mission. Brasília, Workshop de Avaliação, 1992.

HAGE, J.;

FINSTERBUSCH, K.

Organizational change as a development strategy. Boulder : Lynne Rienner, 1987.

HALL, R. H.

Organizations, structure and process. 2. ed. Englewood Cliffs, NJ : Prentice Hall, 1977.

NAISBITT, J.;

ABURDENE, $P$.

Megatrends 2000. São Paulo : Amana-Kay, 1990.

PRICE, J. L.

Handbook of organizational measurement. Lexington : Heath, 1972.

QUIRINO, T. R.;

CRUZ, E. R.;

SOUZA, G. S.

$O$ processo de produção de conhecimento em organizações de pesquisa agropecuária : diagnóstico de projetos. Brasília : EMBRAPA/SEA, 1992. Versão prelim.

SILVA, J. S.;

FLORES, M. X.

Strategic management of agricultural research : the EMBRAPA experience. Public Administration and Development, v. 13, p. 249-259, 1993.

SOUZA, G. S.;

CRUZ, E. R.;

QUIRINO, T. R.

A program to control quality in agricultural research institutions: a case study. In: REUNIÃO REGIONAL CONJUNTA DA ASSOCIAÇÃO BRASILEIRA DE ESTATÍSTICA E DA ASSOCIAÇÃO BRASILEIRA DE ECONOMETRIA (1993 : Brasília). Anais... Brasília : [s.n.], $1993 \mathrm{a}$.

The measurement and assessment of quality in agricultural research institutions. Scientometrics, v. 28, n. 2, p. 159-182, 1993 b. 